\title{
The temperate phages RP2 and RP3 of Streptomyces rimosus
}

\author{
Helmut Rausch, ${ }^{1}$ Margareta Vešligaj, ${ }^{2}$ Darko PoČta,,${ }^{1}$ Goran Biuković, ${ }^{2}$ Jasenka Pigac, ${ }^{2}$ \\ John Cullum, ${ }^{3}$ Horst SChmieger and Daslav Hranueli ${ }^{2 *}$
}

${ }^{1}$ Institut für Genetik und Mikrobiologie, Universität München, München, Federal Republic of Germany
${ }^{2}$ PLIVA Research Institute, Prilaz baruna Filipovića 89, 41000 Zagreb, Republic of Croatia
${ }^{3}$ LB Genetik, Universität Kaiserslautern, Kaiserslautern, Federal Republic of Germany

(Received 15 March 1993; revised 7 April 1993; accepted 26 April 1993)

\begin{abstract}
The oxytetracycline-producing Streptomyces rimosus strains R6-65 and R7 (ATCC 10970) are lysogenic for the two narrow-host-range phages RP2 and RP3. Both phages are released at low frequency from the lysogenic strains and form plaques on 'cured' $S$. rimosus strains. RP2 and RP3 are of similar shape with flexible tails and contain double-stranded DNA of about $70 \% \mathbf{G}+\mathrm{C}$ with cohesive ends (group B1 of bacteriophage classification). The two phages also have identical, very slow, growth kinetics in $S$. rimosus, with a latent phase of about $6 \mathrm{~h}$ and a rise period of about $4 \mathrm{~h} . \mathrm{RP2}$ and RP3 are heteroimmune and they differ slightly in their size of phage particles and length of DNA (64.7 and $62.4 \mathrm{~kb}$ for RP2 and RP3, respectively). The restriction maps of the two phages are completely different, and hybridization experiments showed only one short region of sequence similarity (less than $430 \mathrm{bp}$ ); the two phages are thus essentially unrelated. Both phages lysogenize their hosts by recombination via defined attachment (att) sites. The positions of the attP sites have been localized on the restriction maps of RP2 and RP3 to restriction fragments of 800 and $300 \mathrm{bp}$, respectively. The prophages did not affect the level of oxytetracycline production or the genetic instability of this trait.
\end{abstract}

\section{Introduction}

Streptomyces rimosus produces the commercially important antibiotic oxytetracycline. It is the genetically best-characterized species among industrially important Streptomyces. Chromosomal genetic maps have been constructed for three strains: M4018, R7 (ATCC 10970) and R6 (Friend \& Hopwood, 1971; Alačević et al., 1973). Classical genetical methods have also been applied to analyse the genetics of oxytetracycline biosynthesis in strains R6 and M4018 (Pigac \& Alačević, 1979; Rhodes et al., 1981). In addition, genes for oxytetracycline production and resistance have been cloned and analysed from derivatives of strain M4018 (Butler et al., 1989; Binnie et al., 1989). S. rimosus strain R6 proved to be genetically unstable, and in this strain the oxytetracycline production and resistance genes are localized at an unstable region of the chromosome (Cullum et al., 1991; Gravius et al., 1993). S. rimosus strains R6, R7 and M4018 contain three related giant linear plasmids, between 280 and $370 \mathrm{~kb}$ in size (Cullum et al., 1991;

* Author for correspondence. Tel. +38 (41) 181959 ; fax +38 (41) 576690 .
B. Gravius, D. Glocker, D. Hranueli \& J. Cullum, unpublished results).

For more than 50 years it has been known that actinophages can attack streptomycetes, but they did not attract much attention until their undesirable interference with industrial fermentations was recognized (Welsch, 1969). More recently, however, considerable advances have been made in the genetic and physical analysis of phages and their interaction with their hosts (Lomovskaya et al., 1980). Streptomyces phages have also been developed as DNA cloning vectors (Chater, 1986).

Interest in $S$. rimosus phages also arose because of problems during industrial fermentations. Ya. I. Rautenstein and collaborators (Rautenstein et al., 1972) reported several cases of lysis of $S$. rimosus cultures of two lysogenic strains (560 and IK) under industrial conditions. However, lysis was not induced by a virulent mutant of the temperate phage but by some lytic factor which seems to consist of at least two enzymes, a lytic and a proteolytic enzyme (Rautenstein et al., 1975). A narrow-host-range virulent phage $\mathrm{RP} 1$ has been described that infects $S$. rimosus strains R6 and R7, and $S$. rimosus mutants with reduced actinophage susceptibility 
Table 1. S. rimosus strains used in this study

\begin{tabular}{lcll}
\hline \multicolumn{1}{c}{ Strain no. } & Genotype & \multicolumn{1}{c}{ Origin } & \multicolumn{1}{c}{ Reference } \\
\hline R7 (ATCC 10970) & RP2, RP3 & ATCC & Alačević et al. (1973) \\
R6-65 & RP2, RP3 & PLIVA Culture Collection & This paper \\
R6-500 & RP3 & Spontaneous derivative of R6-65 & This paper \\
R6-501 & RP2, RP3 & R6-500 lysogenized with RP2 & This paper \\
R6-554 & $r i b-12$ & R6-500 mutagenized by MNNG & Hranueli et al. (1986) \\
R6-554(RP2) & $r i b-12$, RP2 & R6-554 lysogenized with RP2 & This paper \\
R6-554(RP3) & $r i b-12$, RP3 & R6-554 lysogenized with RP3 & This paper \\
& & & \\
\hline
\end{tabular}

were isolated (Vešligaj et al., 1981). Strain R7 proved to be lysogenic for a temperate phage RP2 that infects certain R6 derivatives. The morphology and growth kinetics of RP2 have been described (Hranueli et al., 1979). It was shown that curing of - and subsequent lysogenization with - RP2 did not affect oxytetracycline production in high-producing strains (Hranueli et al., 1983). While performing transfection experiments with temperate Streptomyces phages, another temperate phage (named RP3) was discovered fortuitously.

The question arose as to whether RP2 and RP3 are unrelated phages or variants of the same phage. Moreover, the possible role of the phage RP3 in $S$. rimosus antibiotic production (Hranueli et al., 1983), as well as the implication of both prophages in the genetic instability of $S$. rimosus (Gravius et al., 1993) should be addressed. It is also planned to use RP2 and RP3 for the construction of $S$. rimosus cosmids dependent on in vivo packaging (Morino et al., 1985; Kobler et al., 1991) and integrating phage vectors based on the use of phage attachment sites (attP site) (Kuhstoss et al., 1991; Rausch \& Lehmann, 1991).

In this paper, we report the properties of actinophage RP3. The restriction maps of RP2 and RP3 were determined, the phage attachment sites were localized and a small region of homology between the two phages was mapped.

\section{Methods}

Strains, media and culture conditions. Streptomyces rimosus strains which were used throughout this study are listed in Table 1. S. lividans 66, strain TK64 (Hopwood et al., 1983) was used as a control strain for the estimation of growth kinetics of $\phi \mathrm{C} 31$ (Lomovskaya et al., 1970) and for the determination of $\mathrm{G}+\mathrm{C}$ content of phage RP2 and RP3 DNA. The Escherichia coli strains AB1157 dam-4 (Dreiseikelmann et al., 1979) and JM109 (Yanisch-Perron et al., 1985) were used as hosts for plasmids pIC20H/R (Marsh et al., 1984) and pUC19 (YanischPerron et al., 1985), while the strain SURE (Greener, 1990) was used for cosmid cloning with sCos-1 (Evans et al., 1989). All E. coli strains were maintained in LB medium. Methods for propagation and maintenance of $S$. rimosus stocks and oxytetracycline determination were those described by Hranueli et al. (1979) and Vešligaj et al. (1981). The minimal agar medium (MM) (Alačević et al., 1973), complete agar and liquid media (CM and LM) (Hranueli et al., 1979), liquid medium for antibiotic biosynthesis (Vešligaj et al., 1981) and the complete precultivation liquid medium (CPM) (Pigac et al., 1982) were described previously.

Phage techniques. Conventional methods were adapted and used for phage propagation, purification and assay. Adsorption, one-step growth experiments and electron microscopy were done as described by Hranueli et al. (1979), except that an Opton EM10A electron microscope was used.

DNA isolation and manipulation. Total DNA from Streptomyces strains and actinophages were isolated using methods described by Hopwood et al. (1985). Plasmid and cosmid DNA, isolated from $E$. coli, was purified when necessary by $\mathrm{CsCl}$-ethidium bromide gradient centrifugation (Sambrook et al., 1989).

Restriction endonuclease analysis and gel electrophoresis. DNA was digested with restriction enzymes using the supplier's recommended conditions and subjected to horizontal agarose gel electrophoresis in Tris/borate/EDTA buffer. The running conditions - that is the amount of agarose in gels and applied voltage - were selected to give optimal resolution in the molecular weight regions of interest (Sambrook et al., 1989).

DNA labelling and Southern hybridization. Southern blotting was carried out in alkaline conditions using Hy-Bond-N membrane (Amersham) as described by Sambrook et al. (1989). DNA probes were labelled with digoxigenin using a random priming nucleic acid detection kit (Boehringer Mannheim). Hybridization and detection of bands, using a phosphatase kit (Boehringer Mannheim), were carried out under the conditions recommended by the supplier.

Estimation of molecular sizes. Standards were provided by the phage $\lambda$ cI857Sam 7 and phage P22 DNA digested with HindIII, HindIII/ $E c o$ RI and EcoRI, respectively, and by the $1 \mathrm{~kb}$ DNA ladder (GibcoBRL). The reciprocals of the electrophoretic mobilities of the standards from 2 to $15 \mathrm{~kb}$ gave straight lines when plotted against molecular size. However, the fragment sizes, based on analysis of banding patterns on agarose gels, are subject to errors of up to $5 \%$ with fragments of 2 to $15 \mathrm{~kb}$, and higher errors for smaller or larger fragments. Therefore, the fragment sizes in parentheses (see Fig. 3) were determined indirectly by adding sizes from the double digests or by cloning and subsequent restriction-mapping of particular fragments.

Construction and screening of the cosmid gene bank. The cosmid gene bank of $S$. rimosus R6-501 was constructed in E. coli SURE using the vector sCos-1. Sau3A partial digests of $S$. rimosus R6-501 chromosomal DNA were made, while the vector arms were prepared as described by Evans et al. (1989). After reaction with T4 DNA ligase, the ligation mixture was packaged using commercial in vitro packaging lysates (Gigapack Gold, Stratagene). Cloning efficiencies ranged from $1 \times 10^{3}$ to $1 \times 10^{4}$ ampicillin-resistant clones per $\mu \mathrm{g}$ of R6-501 chromosomal DNA. The gene bank was screened for cosmid inserts containing DNA from RP2 or RP3 prophages using DNA from RP2 or RP3 virions, labelled with digoxigenin, as hybridization probes. 
(a)

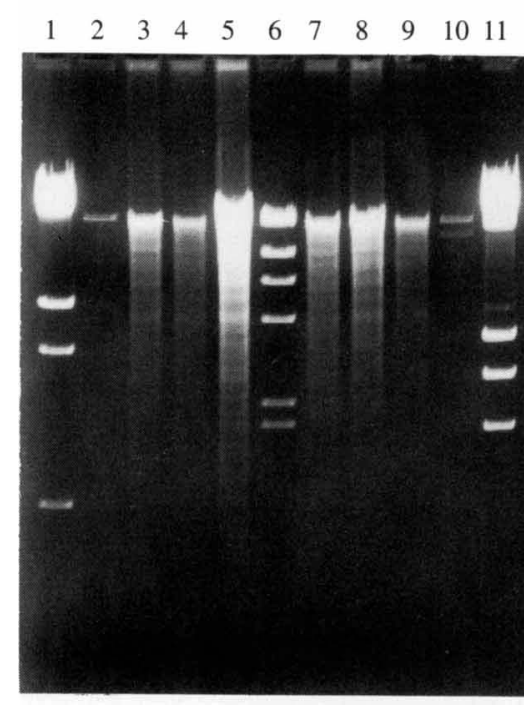

(b)

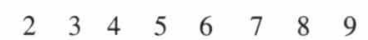

(c)

Fig. 1. (a) Agarose-gel electrophoresis of BglII digests of chromosomal DNA of the $S$. rimosus strains hybridized with RP2 and RP3 DNA. Track 3, R6-65; track 4, R6-500; track 5, R6-554; track 7, R6-554(RP2); track 8, R6-554(RP3); track 9, R7. Tracks 1 and 2, RP2 DNA (3000 ng) and RP2 DNA (30 ng), respectively. Tracks 10 and 11, RP3 DNA (30 ng) and RP3 DNA (3000 ng), respectively. Track 6, $\lambda$ DNA digested with HindIII. (b) Southern transfer of gel hybridized with RP2 DNA as a probe. (c) Southern transfer of gel hybridized with RP3 DNA as a probe.

Hybridization probes for the ends of cosmid inserts. The inserts are flanked by T3- and T7-promoter sites in the vector (Evans et al., 1989). End-specific RNAs were synthesized by in vitro transcription, using bacteriophage T3 or T7 polymerase, from the DNA inserts isolated from individual cosmid clones digested with EcoRI and SalI or PstI. They were labelled with digoxigenin using an RNA labelling kit (Boehringer Mannheim) under the supplier's recommended conditions.

Estimation of phage DNA $G+C$ content. Estimations of RP2 and RP3 DNA $\mathrm{G}+\mathrm{C}$ content were done in $\mathrm{CsCl}$-bisbenzimide gradients (bisbenzimide: Hoechst dye \#33258, Sigma) as described by Raeder \& Broda (1988). $\lambda$ DNA (about 50\% G + C; Sanger et al., 1982) was used as a control, while DNAs from $S$. lividans TK64 and S. rimosus R6-501 (Streptomyces contain about 69-75\% G+C; Chater, 1980) were used as markers.

\section{Results}

\section{Prophages of Streptomyces rimosus}

Phage RP2 was originally detected because it is released from S. rimosus R7 (ATCC 10970) and forms turbid plaques on S. rimosus R6 (Hranueli et al., 1979). Later experiments showed that although the indicator strain routinely used in the laboratory (R6-500) plated the phage, an ancestor of the strain (R6-65) did not allow growth of RP2 and released a phage indistinguishable from RP2 in immunity, morphology of phage particles, plaque morphology and growth kinetics. Southern hybridization experiments, using labelled RP2 DNA as a probe, showed that R7 and R6-65 had identical hybridizing $B g I I I$ fragments, whereas R6-500 showed no hybridization (Fig. 1a,b). S. rimosus strains R6 and R7 have been maintained in the PLIVA laboratories for more than 30 years. However, a new culture of R7 obtained from ATCC showed indistinguishable hybridization patterns (data not shown).

During experiments using a further derivative strain, $S$. rimosus R6-554, as an indicator strain, plaques were observed that proved to be due to release from R6-500 of a new phage named RP3. RP3 produced turbid plaques in a lawn of S. rimosus R6-554. Lysogens can be isolated from such plaques which spontaneously release phage $\mathrm{RP} 3$ and are immune to RP3. S. rimosus $\mathrm{R} 7$ also releases a phage which is homoimmune to RP3. Southern hybridization experiments using labelled RP3 DNA showed identical $B g l \mathrm{II}$ fragments in R6-65, R6-500 and $\mathrm{R} 7$, and confirmed the absence of RP3 in R6-554 (Fig. $1 a, c)$.

Strain R6-554 is a derivative of R6-500 and lacks both prophages (Fig. 1). This strain was artificially lysogenized with RP2 and RP3, respectively (Fig. 1) to demonstrate that RP2 and RP3 were heteroimmune, i.e. RP3 is able to form plaques on RP2 lysogens and vice versa. It was also shown that RP2 and RP3 are both heteroimmune to the three phages $\phi \mathrm{C} 31, \mathrm{R} 4$ and $\mathrm{SH} 10$; the first belongs to immunity group I, while the last two belong to immunity group IV (Lomovskaya et al., 1980).

R6-554 and its lysogenic derivatives are low producers of the antibiotic oxytetracycline. However, work with high producing derivatives showed that the curing of both prophages did not affect production (data not shown). 


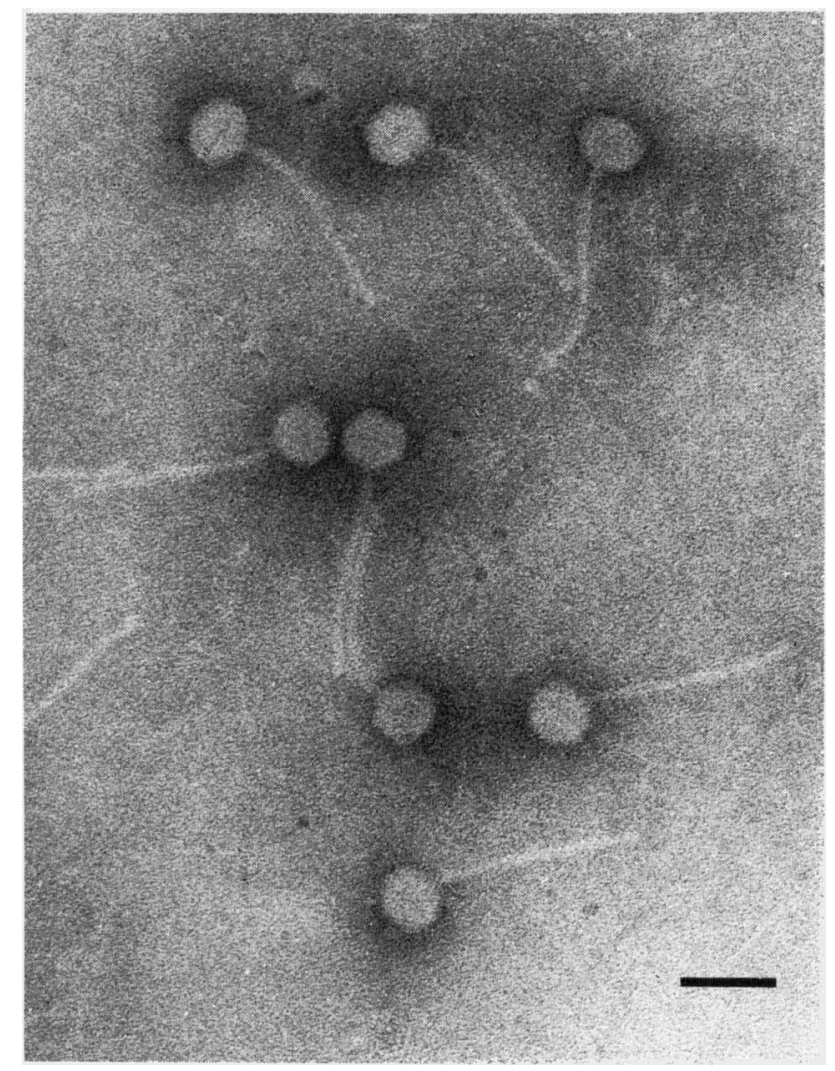

Fig. 2. Electron micrograph of RP3 particles negatively stained with potassium phosphotungstate. Bar, $100 \mathrm{~nm}$.

\section{Morphology and growth kinetics of RP3}

Examination of RP3 lysates by electron microscopy revealed tadpole-shaped particles with hexagonal heads and long, flexible, non-contractile tails (Fig. 2). Measurements of about 50 particles indicated an average head diameter of $68.5 \pm 1.90 \mathrm{~nm}$, a tail length of $216 \pm 4.75 \mathrm{~nm}$ and a tail width of $12.0 \pm 0.75 \mathrm{~nm}$. Statistical analysis using Student's $t$-test showed that these three dimensions are all significantly different (at the $1 \%$ level) from those of RP2 $(71.6 \pm 1.55 \mathrm{~nm}, 245 \pm 5.40 \mathrm{~nm}, 14.9 \pm 0.75 \mathrm{~nm})$ obtained in parallel experiments.

Propagation of phage RP2 is not dependent on the presence of divalent cations in the growth medium (Hranueli et al., 1979). However, optimal growth of RP3 depends on the presence of both $\mathrm{Mg}^{2+}(10 \mathrm{mM})$ and $\mathrm{Ca}^{2+}$ (5 mM) ions (data not shown). Phage RP2 has an unusually long life cycle. One-step growth experiments give a value of $6 \mathrm{~h}$ for the minimum latent period, followed by a $4 \mathrm{~h}$ period of increase (Hranueli et al., 1979). The latent and rise periods of phage RP3 were indistinguishable from those of RP2 (data not shown). Since both RP2 and RP3 life cycles were determined using mycelial fragments of $S$. rimosus R6-500 or its mutant R6-554, the question arose whether long life cycles are the result of phage properties or of some feature(s) of their host. To answer this question experiments were performed in which the broad-host-range phage $\phi$ C31 (Lomovskaya et al., 1970) was grown using both $S$. rimosus R6-554 and S. lividans TK64 as hosts. No differences were observed between the two hosts in latent and rise periods of $\phi \mathrm{C} 31$ (data not shown), which corresponded to published values using $S$. coelicolor A3(2) (Novikova et al., 1973). This showed that the long phage life cycles of RP2 and RP3 are not an automatic consequence of growth on $S$. rimosus.

The host-range of phage RP2 is narrow, restricted to S. rimosus strain R6 (Hranueli et al., 1979). Examination of RP3 lysates, using more than 20 Streptomyces species, showed that phage RP3 had an identical narrow hostrange (data not shown).

\section{Characterization of phage DNA}

DNA was prepared from both phages and subjected to CsCl-bisbenzimide gradient centrifugation to estimate $\mathrm{G}+\mathrm{C}$ content (Raeder \& Broda, 1988), with DNA from phage $\lambda$ (about $50 \% \mathrm{G}+\mathrm{C}$; Sanger et al., 1982) in each tube as a control (data not shown). The DNA from both phages banded lower than the $\lambda$ DNA, showing that it has a higher $\mathrm{G}+\mathrm{C}$ content. The positions of the bands for each phage were comparable to the positions of DNA of $S$. lividans TK64 and S. rimosus R6-501, which were centrifuged in parallel tubes. We estimated the $\mathrm{G}+\mathrm{C}$ contents of the two phages as $70 \%$ (RP2) and $69 \%$ (RP3), assuming that $S$. lividans TK64 total DNA was $72 \% \mathrm{G}+\mathrm{C}$. The gradient method should reveal differences in $\mathrm{G}+\mathrm{C}$ content greater than $3 \%$.

Restriction maps were constructed for each phage genome using five different restriction enzymes. Analysis of single, partial and double digests allowed the alignment of fragments and the estimation of the size of the entire RP2 and RP3 DNA (Fig. 3).

DNA from phages RP2 and RP3 showed completely different restriction patterns. The sizes of the phage genomes were estimated as $64.7 \mathrm{~kb}$ (for RP2) and $62.4 \mathrm{~kb}$ (for RP3) (Fig. 3). In restriction digests, association of the end fragments was seen for both RP2 and RP3, indicating the presence of cohesive ends (data not shown).

\section{Localization of phage attachment sites}

A cosmid gene bank of more than 8000 clones of R6-501 was constructed in the vector sCos-1 (Evans et al., 1989). RP2 DNA was used as a hybridization probe to isolate cosmid clones carrying prophage sequences. Eight positive clones were isolated from 925 colonies tested. Comparison of EcoRI digests of the cosmid clones with the phage restriction map allowed ordering of the clones into a series of overlapping cosmids covering the whole 
(a)

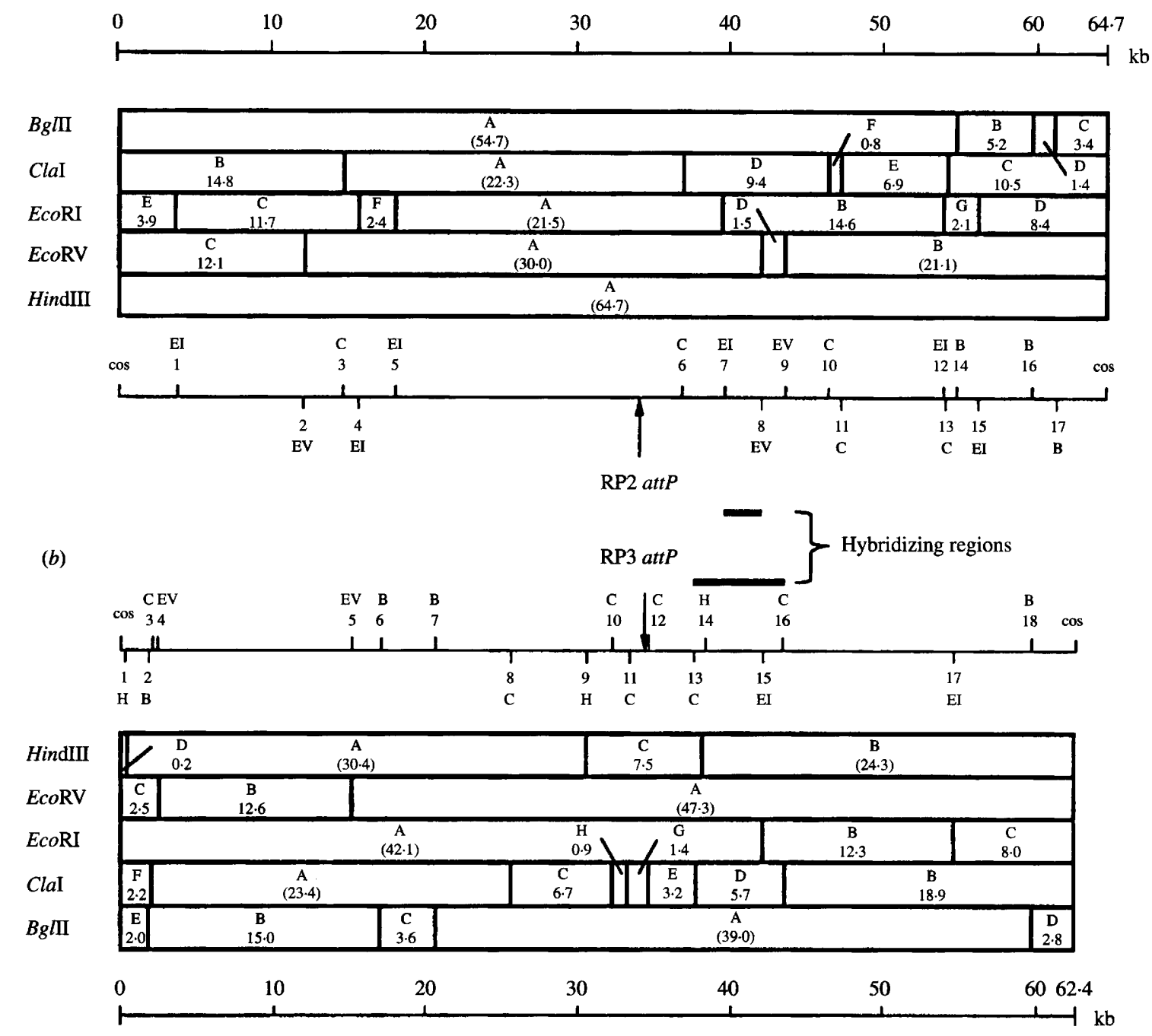

Fig. 3. Restriction maps of RP2 (a) and RP3 (b) DNA. Numbers are used to identify particular sites, and letters are abbreviations for restriction enzyme target sites as follows: B, BgIII C, ClaI; EI, EcoRI; EV, EcoRV; H, HindIII. In the middle part of the diagrams, letters are designations of restriction fragments and numbers are their sizes in $\mathrm{kb}$ (numbers in parentheses were determined indirectly; see Methods).

prophage. The ordering was confirmed by labelling sequences at the end of each insert with digoxigen in using T3 or T7 polymerase (promoters flank the insert) and hybridizing against the cosmid clones and the phage DNA. This also allowed identification of four clones containing the hybrid attachment sites ( $a t t L$ and $a t t R)$ at each end of the prophage. This shows that the attP site must be in the EcoRI-A fragment of RP2 (data not shown) (see Fig. 3).

Similarly, using RP3 DNA, eight positive clones were isolated from the cosmid gene bank. Analysis with $E c o$ RI showed that six of these clones contained hybrid $a t t L$ and $a t t R$ sites and localized the attP site to the EcoRI-A fragment of RP3 (data not shown) (see Fig. 3).
For more detailed localization of the attP regions of both phages, a series of Southern blot analyses were carried out. The phage DNA and the total genomic DNA of the $S$. rimosus strain, lysogenized with the corresponding phage, were digested by the same restriction enzyme, separated on a gel, blotted and hybridized against labelled phage DNA. The attP site of RP2 could be localized to a $5 \mathrm{~kb}$ PvuII fragment (data not shown), which was cloned into pIC20H (pKG11) and a restriction map was constructed for the enzymes BamHI, KpnII, PstI and SalI. The $5 \mathrm{~kb}$ PvuII fragment was used as a hybridization probe against total DNA of R6-554 (RP2) digested with PvuII. The results (Fig. $4 a, b$, lanes 2 and 3) confirmed that the attP site was 
(a)

(b)

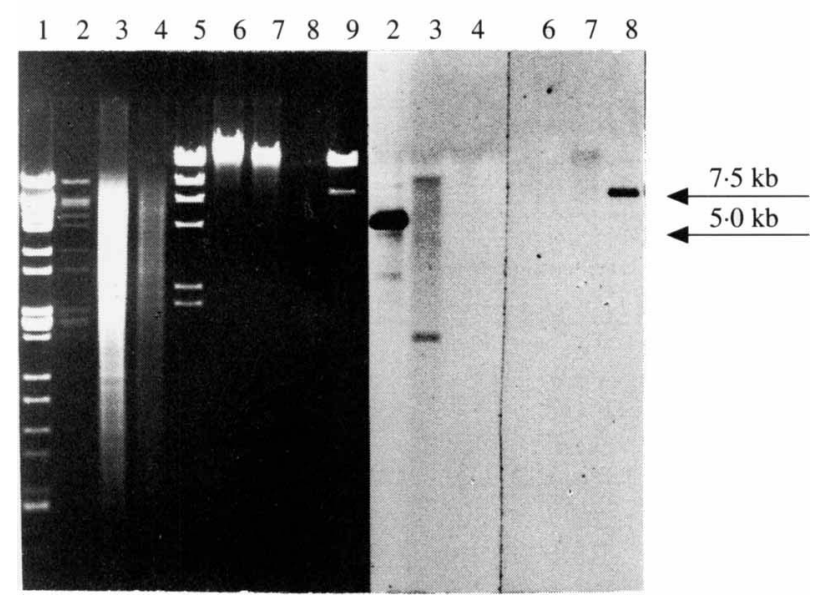

Fig. 4. RP2 and RP3 restriction fragments carrying att $P$ sites. Arrows with numbers indicate phage DNA fragments that contain att $P$ sites. (a) Agarose-gel electrophoresis of PvuII digests of RP2 DNA (4000 ng) (track 1), RP2 DNA (40 ng) (track 2), chromosomal DNA of the $S$. rimosus strains R6-554(RP2) (track 3) and R6-554 (track 4), and of HindIII digests of chromosomal DNA of the $S$. rimosus strains R6-554 (track 6) and R6-554(RP3) (track 7), RP3 DNA (10 ng) (track 8) and RP3 DNA (1000 ng) (track 9). Track 5, $\lambda$ DNA digested with HindIII. (b) Southern transfer of tracks $2-4$ hybridized with RP2 DNA $5 \mathrm{~kb}$ PvuII fragment as a probe. (c) Southern transfer of tracks 6-8 hybridized with RP3 DNA $7.5 \mathrm{~kb}$ HindIII-C fragment as a probe.

(a) RP2 DNA PvuII $(5.0 \mathrm{~kb})$

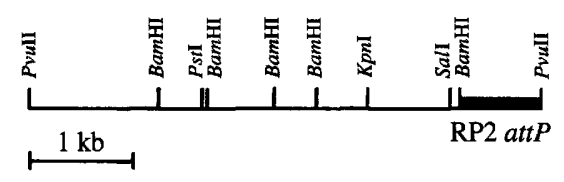

(b) RP3 DNA HindIII-C ( $7.5 \mathrm{~kb})$

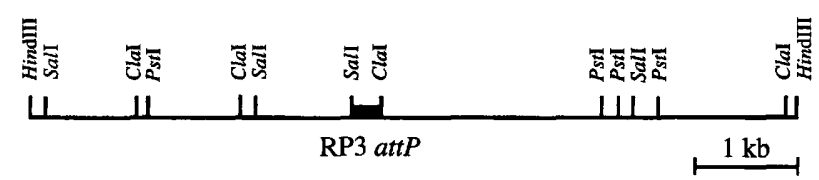

Fig. 5. Localization of the attP sites of RP2 and RP3. The parts of the restriction maps of RP2 (a) and RP3 (b) are in the same orientation as the complete maps shown in Fig. 3. The $5 \mathrm{~kb} P v u \mathrm{II}$ fragment of RP2 is located between coordinates 28.8 and 33.8 , internal to the EcoRI-A fragment of RP2. The bold lines indicate the restriction fragments containing the attP sites.

indeed located on this fragment. Experiments using BamHI, PstI and SalI (data not shown) localized the attP site to a $800 \mathrm{bp}$ Bam HI-PvuII subfragment as shown in Fig. 5(a). The EcoRI-A fragment was cloned into pUC19 (pAZ24) and a restriction map constructed for KpnI and PvuII (data not shown), which localized the (a)

(b)

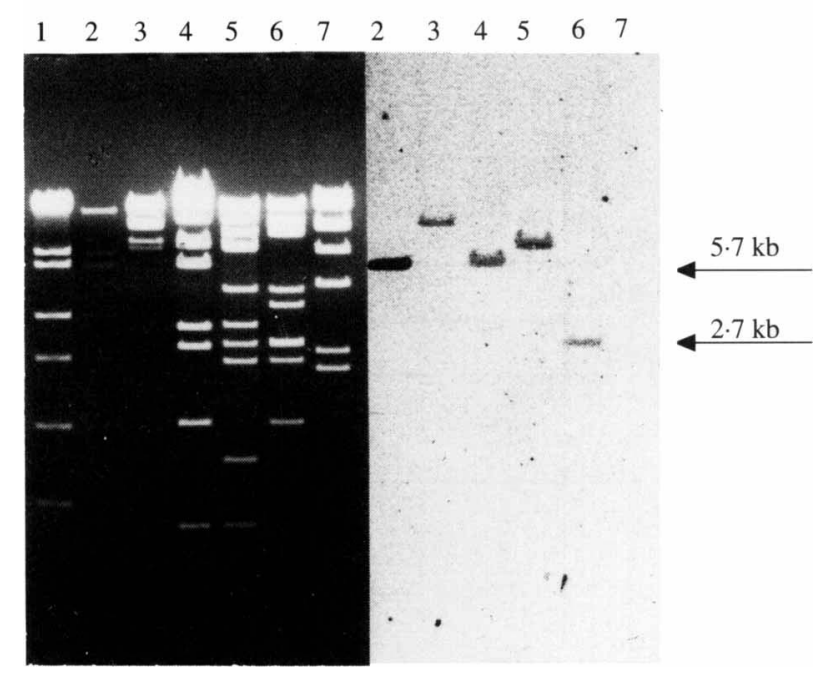

Fig. 6. (a) Agarose-gel electrophoresis of single and double digests of RP2 DNA. Arrows with numbers indicate the smallest RP2 and RP3 DNA fragments that show DNA homology. Track 3, ClaI; track 4, ClaI/EcoRV; track 5, ClaI/EcoRI; track 6, EcoRI/EcoRV. Tracks 1 and 2, RP3 DNA (2000 ng) and RP3 DNA (20 ng) digested with ClaI, respectively. Track $7, \lambda$ DNA digested with HindIII. (b) Southern transfer of gel hybridized with RP3 ClaI-D fragment, isolated from pKG18, as a probe.

$5 \mathrm{~kb} P v u \mathrm{II}(a t t P)$ fragment to the coordinates $28 \cdot 8-33 \cdot 8$ (Fig. $3 a$ ).

Analogous experiments localized the attP site of RP3. Southern transfers of HindIII digests of R6-554(RP3) were hybridized with labelled RP3 DNA. This showed that integration had occurred within the $7.5 \mathrm{~kb} H$ indIII$\mathrm{C}$ fragment (data not shown). This fragment was cloned into pIC20R (pKG1) and subjected to restriction analysis with ClaI, PstI and SalI. However, when the $7.5 \mathrm{~kb}$ HindIII fragment was used as a probe, only one new hybridization signal could be seen (Fig. $4 a, c$, lanes 7 and 8 ). This is most likely due to the large size of both new fragments appearing in the DNA of R6-554(RP2), which would not be resolved in the gel system used. Further Southern hybridization experiments localized the attP site to a $300 \mathrm{bp} \mathrm{ClaI-SalI} \mathrm{subfragment} \mathrm{as} \mathrm{shown} \mathrm{in}$ Fig. $5(b)$.

\section{Homology between RP2 and RP3}

Southern hybridization experiments to check the lysogenic status of strains suggested that there was DNA homology between the largest $B g I I I$ fragments of RP2 and RP3. However, when hybridizations were carried out using total phage DNA, only weak hybridization was observed between the two phages. On the other hand, no hybridization of RP2 and RP3 DNA was seen with total DNA of $\phi C 31$ and SH10 (data not shown). 
Localization of possible homology between RP2 and RP3 DNA was difficult because of the size of the fragments concerned. Therefore, appropriate isolated restriction fragments were used as hybridization probes against single and double digests of the other phage. This showed that the homologous region in RP3 was within the ClaI-D fragment and this $5.7 \mathrm{~kb}$ fragment was cloned in pIC20R (pKG18). Fig. 6 shows the results of hybridizing restriction digests of RP2 DNA with the ClaI-D fragment of RP3 as a probe. It can be seen that the weak cross-homology is confined to a $2.7 \mathrm{~kb}$ $E c o$ RI-EcoRV fragment of RP2 (see also the restriction map in Fig. 3). This $2.7 \mathrm{~kb}$ fragment was cloned in pIC20R (pHR121). Further experiments localized the homology region in RP2 to a 430 bp SmaI subfragment near the right-hand end of this $2.7 \mathrm{~kb}$ fragment and in RP3 to a 800 bp ClaI-SalI subfragment at the left-hand end of the ClaI-D fragment (data not shown).

\section{Discussion}

The results presented in this paper show that both $S$. rimosus R6-65 and R7 (ATCC 10970) are lysogenic for the two heteroimmune, narrow-host-range prophages RP2 and RP3 (Fig. 1). Strains R6 and R7 had been maintained in the PLIVA laboratories for a very long time before the phages were identified. The question arose as to whether these two strains were lysogenic as original isolates, or whether fortuitous lysogenization has resulted during the long-term maintenance of strains in the same laboratory. Experiments using a culture of R7 newly obtained from ATCC are in favour of the genuine lysogenic nature of $S$. rimosus $\mathrm{R} 7$. This is further supported by the observation of Voeykova et al., (1988) who reported the presence of phage-like particles during electron microscope studies of $S$. rimosus ATCC 10970 cultures. However, the nature of these particles is not completely clear as they probably did not have suitable cured host strains for phage propagation. Since the original isolate of the strain R6 is no longer available, the fortuitous lysogenization of the $S$. rimosus R6 by the temperate actinophages RP2 and RP3 from $S$. rimosus R7 cannot be excluded.

The tadpole-shaped morphology (Fig. 2; Hranueli et al., 1979) and double-stranded DNA content of RP2 and RP3 particles placed them in group B1 of the bacteriophage taxonomic classification (Ackermann \& DuBow, 1987). Small but significant differences in size of the phage particles between RP2 and RP3 were seen. Although the latent periods of actinophageactinomycete systems are usually very long (typically about $1 \mathrm{~h}$ ), RP2 and RP3 - with their $6 \mathrm{~h}$ latent periods - are the slowest multiplying actinophages so far described (Lomovskaya et al., 1980). This was not due to the $S$. rimosus host strain alone, as the broad-host-range phage $\phi \mathrm{C} 31$ showed normal growth kinetics on $S$. rimosus.

The two phage genomes have different restriction patterns, but are of comparable size $(64.7 \mathrm{~kb}$ and $62.4 \mathrm{~kb}$ for RP2 and RP3, respectively) (Fig. 3), and have a similar high $\mathrm{G}+\mathrm{C}$ content (about $70 \%$ ). Both phages have cohesive ends implying site-specific staggered cutting of concatemeric DNA probably resulting from 'rolling circle' replication (Chater, 1980), but there is little homology between them. Therefore, actinophages RP2 and RP3 are essentially unrelated phages. Taken together these properties make them ideal high $\mathrm{G}+\mathrm{C}$ content DNA markers when using pulsed-field electrophoresis to map G+C-rich DNA (B. Gravius, J. Cullum \& D. Hranueli, unpublished results).

Both RP2 and RP3 lysogenize by recombination at an att site (Fig. 3) and the positions of the phage att $P$ sites were determined to within $800 \mathrm{bp}$ and $300 \mathrm{bp}$, respectively (see Fig. $5 a, b$ ). The sequences of the attP sites will be determined, and the construction of integrating vectors, analogous to those constructed with $\phi \mathrm{C} 31$ (Kuhstoss et al., 1991; Rausch \& Lehmann, 1991), is in progress. The availability of several independent integrating vectors for $S$. rimosus would be very advantageous for complementation studies. Furthermore, since genes coding the biosynthesis of oxytetracycline in $S$. rimosus $\mathrm{R} 6$ are located in an unstable region of the chromosome (Gravius et al., 1993), such vectors will be used to reintroduce useful genes into more stable regions.

With the help of the phage restriction maps (Fig. 3), it will be possible to clone the $\cos$ sites, sequence them and to construct cosmid vectors analogous to those for R4 and $\phi$ C31 (Morino et al., 1985; Kobler et al., 1991).

Although RP2 and RP3 do not show extensive homology (see restriction maps, Fig. 3 and Fig. 6), it was possible to localize a specific homologous region to restriction fragments of $430 \mathrm{bp}$ and $800 \mathrm{bp}$, respectively. In both phages, the homology lies near the attachment site and it is hoped that DNA sequencing will indicate whether a conserved function is present.

RP2 and RP3 were only detected because the extensive genetic investigations with $S$. rimosus led to the fortuitous generation of cured strains. It is likely that lysogens occur in many other strains but have not been detected, and the presence of further prophages in $S$. rimosus cannot be ruled out. Further studies on the biology of RP2 and RP3 will not only be useful for the genetic manipulation of $S$. rimosus, but will form a model system for a more general understanding of the role of prophages in Streptomyces.

This work was supported by the Cooperation grant between the 'Ludwig-Maximilians-Universität München', Federal Republic of Germany, and the University of Zagreb, Republic of Croatia (to H.S. 
and D.H.) and partially by the EC International Scientific Cooperation grant [no. CI1*/0527-C (MB)] (to J.C. and D.H.), by Deutsche Forschungsgemeinschaft (Schm 313/10) (to H.S.) and by the grant (no. 1-08-021) (to D.H.) from the Ministry of Science, Technology and Informatics, Republic of Croatia. We thank the Ministry of Science, Technology and Informatics, Republic of Croatia for financial support for graduate student (to G. B.). The electron micrograph preparation of RP3 viral particles by Dalia Matijević and Dr. Nikola Ljubešić is gratefully acknowledged. We are also indebted to Ute Schmidt, Helena Kobelšćak and Višnja Horvat for their skilled technical assistance.

\section{References}

Ackermann, H.-W. \& Dubow, M. S. (1987). Viruses of Prokaryotes, vol. 1, General Properties of Bacteriophages. Boca Raton: CRC Press.

Alačević, M., Strašek-Vešligaj, M. \& Sermonti, G. (1973). The circular linkage map of Streptomyces rimosus. Journal of General Microbiology 77, 173-185.

BINNIE, C., WARREN, M. \& BUtler, M. J. (1989). Cloning and heterologous expression in Streptomyces lividans of Streptomyces rimosus genes involved in oxytetracycline biosynthesis. Journal of Bacteriology 171, 887-895.

Butler, M. J., Friend, E. J., Hunter, I. S., Kaczmarek, F. S., SUDGEN, D. A. \& WARREN, M. (1989). Molecular cloning of resistance gene and architecture of a linked gene cluster involved in biosynthesis of oxytetracycline by Streptomyces rimosus. Molecular and General Genetics 215, 231-238.

ChATER, K. F. (1980). Actinophage DNA. Developments in Industrial Microbiology 21, 65-74.

CHATER, K. F. (1986). Streptomyces phages and their applications to Streptomyces genetics. In The Bacteria, vol. 9, Antibiotic-Producing Streptomyces, pp. 119-158. Edited by S. W. Queener \& L. E. Day. New York: Academic Press.

Cullum, J., Flett, F., Gravius, B., Hranueli, D., Miyashita, K., Pigac, J., Rauland, U. \& Redenbach, M. (1991). Analysis of amplifications and deletions in Streptomyces species. In Genetics and Product Formation in Streptomyces, pp. 265-272. Edited by S. Baumberg, H. Krügel \& D. Noack. New York: Plenum Press.

DreiseikelmanN, B., Eichenlaub, R. \& WaCkernagel, W. (1979). The effect of differential methylation by Escherichia coli of plasmid DNA and phage T7 and $\lambda$ DNA on the cleavage by restriction endonuclease MboI from Moraxella bovis. Biochimica et Biophysica Acta 562, 418-428.

Evans, G. A., Lewis, K. \& RothenberG, B. E. (1989). High efficiency vectors for cosmid microcloning and genomic analysis. Gene $\mathbf{7 9}$, 9-20.

Friend, E. J. \& Hopwood, D. A. (1971). The linkage map of Streptomyces rimosus. Journal of General Microbiology 68, 187-197.

Gravius, B., Bezmalinović, T., Hranueli, D. \& Cullum, J. (1993). Genetic instability and strain degeneration in Streptomyces rimosus. Applied and Environmental Microbiology 59, 2220-2228.

GrEENER, A. L. (1990). Recombination, repair and endonuclease deficient Escherichia coli as stable cloning host. Stratagene 3, 5-6.

Hopwood, D. A., Kieser, T., Wright, H. M. \& BiBB, M. J. (1983). Plasmids, recombination and chromosome mapping in Streptomyces lividans 66. Journal of General Microbiology 129, 2257-2269.

Hopwood, D. A., BibB, M. J., Chater, K. F., Kieser, T., Bruton, C. J., Kieser, H. M., Lydiate, D. J., Smith, C. P., WARD, J. M. \& SCHREMPF, H. (1985). Genetic Manipulation of Streptomyces: A Laboratory Manual. Norwich: John Innes Foundation.

Hranueli, D., Pigac, J. \& Vešligaj, M. (1979). Characterization and persistence of actinophage RP2 isolated from Streptomyces rimosus ATCC 10970. Journal of General Microbiology 114, 295-303.

Hranueli, D., SMokvina, T. \& AlaČEviĆ, M. (1986). A comparative study of protoplast preparation and regeneration in Streptomyces rimosus and Streptomyces lividans. Microbiologica 9, 387-392.
Hranueli, D., Fillpović, M., Pigac, J. \& Vešligaj, M. (1983). The interference of prophage with the biosynthesis of antibiotic. Kemija $u$ industriji (Zagreb) 32, 401-404.

Kobler, L., SchWertfirm, G., Schmieger, H., Bolotin, A. \& SLADKova, I. (1991). Construction and transduction of a shuttle vector bearing the cos site of Streptomyces phage $\phi \mathrm{C} 31$ and determination of its cohesive ends. FEMS Microbiology Letters 78 , 347-354.

Kuhstoss, S., Richardson, M. A. \& Rao, R. N. (1991). Plasmid cloning vectors that integrate site-specifically in Streptomyces spp. Gene 97, 143-146.

Lomovskaya, N. D., Chater, K. F. \& Mkrtumian, N. M. (1980) Genetics and molecular biology of Streptomyces bacteriophages. Microbiological Reviews 44, 206-229.

Lomovskaya, N. D., Mkrtumian, N. M. \& Gostimskaya, N. L. (1970). Isolation and characteristics of Streptomyces coelicolor actinophage. Genetika 6, 135-137.

MARSh, J. L., ERfLe, M. \& WyKES, E. J. (1984). The pIC plasmid and phage vectors with versatile cloning sites for recombinant selection by insertional inactivation. Gene 32, 481-485.

Morino, T., Takahashi, H. \& SaITo, H. (1985). Construction and characterization of a cosmid of Streptomyces lividans. Molecular and General Genetics 198, 228-233.

Novikova, N. L., Lomovskaya, N. D. \& Kapitonova, O. N. (1973). Adsorption and growth of actinophage $\phi \mathrm{C} 31$ in germinating spores of Streptomyces coelicolor A3(2). Mikrobiologiya 42, 513-518.

PIGAC, J. \& AlAČEVIĆ, M. (1979). Mapping of oxytetracycline genes in Streptomyces rimosus. Periodicum Biologorum 81, 575-582.

Pigac, J., Hranueli, D., Smokvina, T. \& Alačević, M. (1982) Optimal cultural and physiological conditions for handling Streptomyces rimosus protoplasts. Applied and Environmental Microbiology 44, 1178-1186.

RAEDER, U. \& BRoDA, P. (1988). Preparation and characterization of DNA from lignin-degrading fungi. Methods in Enzymology 161, 211-220.

Rausch, H. \& LehmanN, M. (1991). Structural analysis of the actinophage $\phi \mathrm{C} 31$ attachment site. Nucleic Acids Research 19, 5187-5189.

Rautenstein, Ya. I., Zhunaeva, V. V., Khokhlova, Yu. M., NestEROVA, N. G. \& MOSKALENKo, L. N. (1975). Factors inducing lysis of Actinomyces rimosus producing oxytetracycline. Mikrobiologiya 44 899-904.

Rautenstein, Ya. I., Borisova, T. G., Goldat, S. Yu., Zhunaeva, V. V., Vladimirov, A. V., Moskalenko, L. N., Terebkova, L. S., ISAIKINA, L. S. \& MisiureVA, N. G. (1972). Lysis in the culture of Actinomyces rimosus. Mikrobiologiya 41, 1055-1063.

Rhodes, P. M., Winskill, N., Friend, E. J. \& Warren, M. (1981). Biochemical and genetic characterization of Streptomyces rimosus mutants impaired in oxytetracycline biosynthesis. Journal of General Microbiology 124, 329-338.

SambrooK, J., Fritsch, E. F. \& Maniatis, T. (1989). Molecular Cloning: A Laboratory Manual, 2nd edn. Cold Spring Harbor, NY: Cold Spring Harbor Laboratory.

Sanger, F., Coulson, A. R., Hong, G. F., Hill, D. F. \& Petersen, G. B. (1982). Nucleotide sequence of bacteriophage lambda DNA. Journal of Molecular Biology 162, 729-773.

Vešligaj, M., Filipović, M., Pigac, J. \& Hranueli, D. (1981) Isolation of Streptomyces rimosus mutants with reduced actinophage susceptibility. Applied and Environmental Microbiology 41, 986-991.

Voeykova, T. A., Mkrtumian, N. M., Emelyanova, L. K. \& LomovSKAYA, N. D. (1988). Relationship between actinophages and industrial strains of actinomycetes. Biotechnologiya 4, 176-182.

WelsCH, M. (1969). Biology of actinophages. In Genetics and Breeding of Streptomyces, pp. 43-62. Edited by G. Sermonti \& M. Alačević. Zagreb: Yugoslav Academy of Sciences and Arts.

YaNISCh-PerRon, C., Vieira, J. \& Messing, J. (1985). Improved M13 phage vectors and host strains: nucleotide sequences of the M13mp18 and pUC19 vectors. Gene 33, 103-119. 